Wilfrid Laurier University

Scholars Commons @ Laurier

$1-1983$

\title{
Effects of Obesity-Inducing Ventromedial Hypothalamic Lesions on Pulsatile Growth Hormone and Insulin Secretion: Evidence for the Existence of a Growth Hormone-Releasing Factor
}

Rudy Eikelboom

Wilfrid Laurier University, reikelboom@wlu.ca

Gloria Shaffer Tannebaum

Montreal Children's Hospital

Follow this and additional works at: https://scholars.wlu.ca/psyc_faculty

\section{Recommended Citation}

Eikelboom, Rudy and Shaffer Tannebaum, Gloria, "Effects of Obesity-Inducing Ventromedial Hypothalamic Lesions on Pulsatile Growth Hormone and Insulin Secretion: Evidence for the Existence of a Growth Hormone-Releasing Factor" (1983). Psychology Faculty Publications. 10.

https://scholars.wlu.ca/psyc_faculty/10

This Article is brought to you for free and open access by the Psychology at Scholars Commons @ Laurier. It has been accepted for inclusion in Psychology Faculty Publications by an authorized administrator of Scholars Commons@ Laurier. For more information, please contact scholarscommons@wlu.ca. 


\title{
Effects of Obesity-Inducing Ventromedial Hypothalamic Lesions on Pulsatile Growth Hormone and Insulin Secretion: Evidence for the Existence of a Growth Hormone-Releasing Factor*
}

\author{
ROELOF EIKELBOOM $\dagger$ AND GLORIA SHAFFER TANNENBAUM $\ddagger$ \\ Division of Endocrinology, Department of Medicine, McGill University-Montreal Children's Hospital \\ Research Institute, and the Departments of Pediatrics, and Neurology and Neurosurgery, McGill \\ University, Montreal, Quebec H3H 1P3, Canada
}

\begin{abstract}
The nature of and neural mechanisms involved in $\mathrm{GH}$ and insulin responses to obesity-inducing ventromedial hypothalamic (VMH) lesions, which infringed on the arcuate nucleus, were examined in freely moving chronically cannulated male rats. Sequential 6-h GH and 3-h insulin and glucose secretory profiles were obtained in VMH-lesioned and sham-operated control rats. Obese VMH rats exhibited hyperinsulinemia with marked fluctuations in plasma insulin levels in the presence of normoglycemia. A striking suppression in both amplitude and duration of GH secretory episodes was observed, with GH peak amplitudes rarely exceeding $90 \mathrm{ng} / \mathrm{ml}$ compared to $500 \mathrm{ng} / \mathrm{ml}$ in sham-operated controls (mean 6-h plasma GH level, 17.6 \pm 6.0 vs. $154.1 \pm 17.8 \mathrm{ng} / \mathrm{ml} ; P<0.001)$. The periodicity of the $\mathrm{GH}$ rhythm was maintained, but light-dark entrainment of the GH pulses was lost. Passive immunization with a specific antiserum to somatostatin (SRIF) failed to restore the amplitude of the
\end{abstract}

GH peaks or to alter significantly the 6 -h GH secretory profile of VMH-lesioned animals. In contrast, the administration of SRIF antiserum to sham-operated controls caused a significant elevation of GH trough levels. In a second study, obese VMHlesioned rats exhibited reduced pituitary GH concentrations compared to sham-operated controls.

The finding of a lack of effect of SRIF antiserum in VMHlesioned rats provides good evidence that the suppression of $\mathrm{GH}$ pulses observed in response to lesions of the $\mathrm{VMH}$ is due to interruption of stimulatory pathways involved in $\mathrm{GH}$ regulation, namely GH-releasing factor neurons. The results suggest that the ultradian surges of GH release are dependent on the release of GH-releasing factor from the VMH-arcuate nucleus region of the brain. The data are consistent with the view that the obesity and $\mathrm{GH}$ suppression of the VMH syndrome reflect the disruption of two different neuronal systems. (Endocrinology 112: 212, 1983)
$\mathrm{L}^{\mathrm{B}}$ ESIONS of the ventromedial hypothalamus (VMH) result in distinct behavioral and physiological abnormalities (labeled the VMH syndrome), the best known of which are hyperphagia, hyperinsulinemia, and obesity $(1,2)$. Since the first experiments by Hetherington and Ranson (3), it has been well documented that animals with VMH lesions show reduced linear growth (4-7). Subsequent studies have suggested an impairment in $\mathrm{GH}$ secretion, since both weanling $(8,9)$ and adult (10) VMH-lesioned rats exhibit suppressed plasma GH levels. These studies, however, were carried out before delinea-

Received April 2, 1982.

Address requests for reprints to: Dr. Gloria S. Tannenbaum, Department of Endocrinology, Montreal Children's Hospital, 2300 Tupper Street, Montreal, Quebec H3H 1P3, Canada.

* This work was supported by grants from the Medical Research Council of Canada (MA-6837) and the Quebec Medical Research Council. This is publication 82040 of the McGill University-Montreal Children's Hospital Research Institute.

† Fellow of the Quebec Medical Research Council. Current address: Department of Psychology, Queen's University, Kingston, Ontario, Canada.

$\ddagger$ Scholar of the Quebec Medical Research Council. tion of the ultradian rhythm for GH secretion in the rat (11) and were performed in animals that did not exhibit the classic VMH lesion-induced increase in body weight. Furthermore, the mechanism mediating the GH suppression in response to VMH lesions remains to be elucidated. It is currently believed that central nervous system control of GH secretion is achieved via the complex interaction of two hypothalamic hormones: a GH-releasing factor (GRF), as yet unidentified, and a GH releaseinhibiting factor, the tetradecapeptide somatostatin (SRIF) (12). If the GH suppression observed in VMHlesioned rats is due to hypersecretion of SRIF, administration of a specific antiserum to SRIF should result in an immediate and marked recovery of GH secretion, as occurs in other forms of SRIF-mediated GH suppression (13-16). Therefore, the first study in the present report was undertaken to characterize the dynamics of the GH rhythm in obese VMH-lesioned rats and to assess the involvement of endogenous SRIF in this response. Plasma insulin and glucose were simultaneously moni- 
tored. In addition, a second study was designed to investigate changes in the pituitary GH concentration in view of previously reported inconsistencies regarding the effects of VMH lesions on the pituitary GH concentration $(6,8,9,17-19)$.

\section{Materials and Methods}

\section{Animals and surgery}

Adult male Sprague-Dawley rats, weighing $300-350 \mathrm{~g}$ at the start of each experiment, were obtained from Charles River Canada (St. Constant, Quebec). Chronic intracardiac venous cannulae were implanted under sodium pentobarbital $(50 \mathrm{mg} /$ $\mathrm{kg}$, ip) anesthesia, as previously described (11). At the same time, electrodes, made from 00 stainless steel insect pins insulated except for $0.4 \mathrm{~mm}$ at the tip, were stereotaxically inserted, bilaterally, into the VMH. With the incisor bar at $-3 \mathrm{~mm}$, coordinates were: $2.3 \mathrm{~mm}$ posterior to bregma, $0.6 \mathrm{~mm}$ lateral to the midline, and $9.1 \mathrm{~mm}$ below the dura. Lesions were produced using a Grass Lesion Maker (model DCLM5A, Grass Instrument Co., Quincy, MA) and direct anodal currents ranging from $1 \mathrm{~mA}$ for $18 \mathrm{sec}$ to $2 \mathrm{~mA}$ for $15 \mathrm{sec}$. Sham-operated control rats were treated identically to VMH-lesioned rats, but the lesion maker was not turned on.

\section{Experimental procedure}

After surgery, the animals were placed directly in isolation test chambers (lights on between 0600-1800 h). Purina rat chow and tap water were available ad libitum, and body weight was monitored daily. Only lesioned rats exhibiting a daily weight gain more than $3 \mathrm{SD}$ above that of sham-operated controls were selected for study of the classic VMH obese syndrome. After recovery of preoperative body weight (5-11 days for shams; $2-4$ days for VMH-lesioned rats), a 6-h hormonal profile was obtained from both groups of rats by withdrawing blood $(0.45 \mathrm{ml})$ every $15 \mathrm{~min}$ from $1000-1600 \mathrm{~h}$. To assess the role of endogenous SRIF, two additional 6-h profiles were obtained from the VMHlesioned animals. Nine to 13 days postsurgery, VMH-lesioned rats were administered $1 \mathrm{ml}$ normal sheep serum (NSS), iv, after removal of the first blood sample. After a minimum interval of 3 days, these rats received $1 \mathrm{ml}$ of a specific SRIF antiserum (SRIF AS) at the same time point. Sham-operated rats received a similar $1-\mathrm{ml}$ injection of SRIF AS. The SRIF AS used in these experiments was identical to that described in our previous passive immunization studies $(15,16)$. On the test days, food was removed 1.5-2 $\mathrm{h}$ before the start of sampling and returned at $1600 \mathrm{~h}$. All blood samples were immediately centrifuged, and plasma was separated and stored at $-20 \mathrm{C}$ for subsequent assay of GH, insulin, and glucose. While plasma GH levels were measured for the full $6 \mathrm{~h}$, plasma insulin and glucose levels were determined only for the first $3 \mathrm{~h}$.

In the second experiment, two groups of rats received either VMH or sham lesions, as described above. Body weight and 24$h$ food intake were monitored daily, and the same weight criterion was used for inclusion in the VMH-lesioned, obese (VMH-obese) group. Sixteen days after surgery, both groups were killed by rapid decapitation, and trunk blood was collected.
The pituitary gland was removed, weighed, homogenized in 2 $\mathrm{ml} 0.05 \mathrm{M} \mathrm{NaHCO}_{3}-\mathrm{Na}_{2} \mathrm{CO}_{3}$ buffer, $\mathrm{pH} 9.96$, and centrifuged at $2000 \times \mathrm{g}$ for $30 \mathrm{~min}$. The supernatant was removed and stored at $-20 \mathrm{C}$ until subsequent assay for GH.

At the termination of both experiments, the brains of all lesioned animals were stored in 10\% formaldehyde. Coronal sections $(28 \mu \mathrm{m})$ were made and stained with thionine. The extent and location of the lesions were determined by light microscopy, using the atlas of Pellegrino and Cushman (20).

\section{Hormone assays}

Plasma and pituitary rat $\mathrm{GH}$ concentrations were determined in duplicate by double antibody RIA using materials supplied by the NIAMDD (Bethesda, MD). The averaged plasma and pituitary GH values are reported in terms of the rat $\mathrm{GH}$ reference preparation (GH-RP-1). Plasma immunoreactive insulin (IRI) was measured by a dextran-coated charcoal method (21) using guinea pig antiporcine insulin serum. Purified crystalline rat insulin (lot 615-D63-12-2, courtesy of Dr. R. Chance, Eli Lilly Co., Indianapolis, IN) served as a reference standard. Plasma glucose was measured by an automated glucose oxidase method (Glucose Analyzer 2, Beckman Instruments, Palo Alto, $\mathrm{CA})$.

Antibody titers in plasma of rats after the administration of SRIF AS

Antibody titers in plasma of SRIF AS-treated, VMH-lesioned rats were assessed by determining the ability of aliquots of rat plasma obtained $1 \mathrm{~min}$ before and $15 \mathrm{~min}, 3 \mathrm{~h}$, and $6 \mathrm{~h}$ after SRIF AS administration to bind [ ${ }^{125}{ }^{2}-$ Tyr $\left.^{1}\right]$ SRIF. Plasma samples from each rat were diluted 1:100 in the SRIF RIA assay buffer, and binding to labeled SRIF was determined under the conditions used for RIA of SRIF (22).

\section{Statistical analyses}

In the first experiment, overall comparisons between groups were made using an analysis of variance. Individual comparisons after analysis of variance were made using the NewmanKeuls test (23). In the second experiment, statistical comparisons between the two groups were made with Student's twotailed $t$ test.

\section{Results}

\section{Behavioral and histological analyses}

Behaviorally, VMH-obese rats were highly irritable, aggressive, and difficult to handle compared to shamoperated controls. VMH-lesioned animals $(n=6)$ recovered from surgery and gained weight more rapidly than did sham-operated control rats $(\mathrm{n}=7$; mean daily weight gain, $7.2 \pm 0.7$ vs. $3.0 \pm 0.2 \mathrm{~g}$, respectively).

VMH-obese rats exhibited bilateral lesions that destroyed over $80 \%$ of the VMH and also resulted in appreciable damage to the arcuate (ARC) nucleus. A representative coronal section showing the largest extent of a 
typical lesion is illustrated in Fig. 1. The antero-posterior extent was from just caudal to the anterior hypothalamus to just rostral to the lateral mammillary nucleus [6.4-4.8 in the atlas of Pellegrino and Cushman (20)]. The lesions did not extend through the base of the brain, and the median eminence was spared. Laterally, the lesions reached the fornix, and in most animals, the walls of the third ventricle were distended.

\section{Effects of VMH lesions on GH, IRI, and glucose secre- tory profiles}

Figure 2 shows representative 6-h plasma GH and 3-h plasma IRI and glucose secretory patterns in a shamoperated animal in comparison to those in an obeseVMH rat. In sham animals, plasma IRI levels remained low (rarely exceeding $2.0 \mathrm{ng} / \mathrm{ml}$ ) and fluctuated minimally over the 3-h period (Fig. 2A). In contrast, plasma IRI levels in VMH-lesioned rats were markedly elevated and showed wide and rapid fluctuations, with most peak IRI values ranging between $3-10 \mathrm{ng} / \mathrm{ml}$ (Fig. 2B). Mean 3-h plasma IRI levels were significantly elevated in VMH-lesioned rats compared to those in sham-operated controls $(3.59 \pm 0.83$ vs. $0.99 \pm 0.18 \mathrm{ng} / \mathrm{ml} ; P<0.05$; Table 1). Plasma glucose levels remained stable throughout the sampling period in both groups, and no significant difference in the mean 3 -h plasma glucose level was observed (Table 1).

Sham-operated animals exhibited the typical pulsatile pattern of GH secretion; two major episodes of $\mathrm{GH}$ secretion were evident during the 6 -h sampling period. The GH secretory episodes had a rapid onset and were multiphasic in nature, with many peak GH values exceeding $500 \mathrm{ng} / \mathrm{ml}$. Intervening trough levels were generally undetectable $(<6.2 \mathrm{ng} / \mathrm{ml}$, the least detectable concentration in our rat GH assay; Fig. 2A). In striking

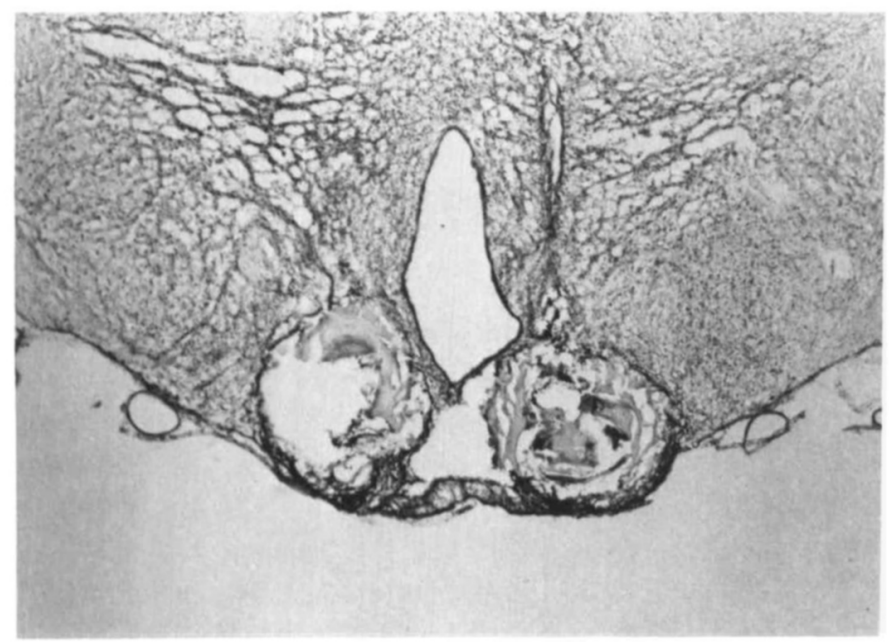

FIG. 1. A photomicrograph $(\times 31)$ of a coronal section of the ventral hypothalamus illustrating the largest extent of a typical bilateral electrolytic VMH lesion.

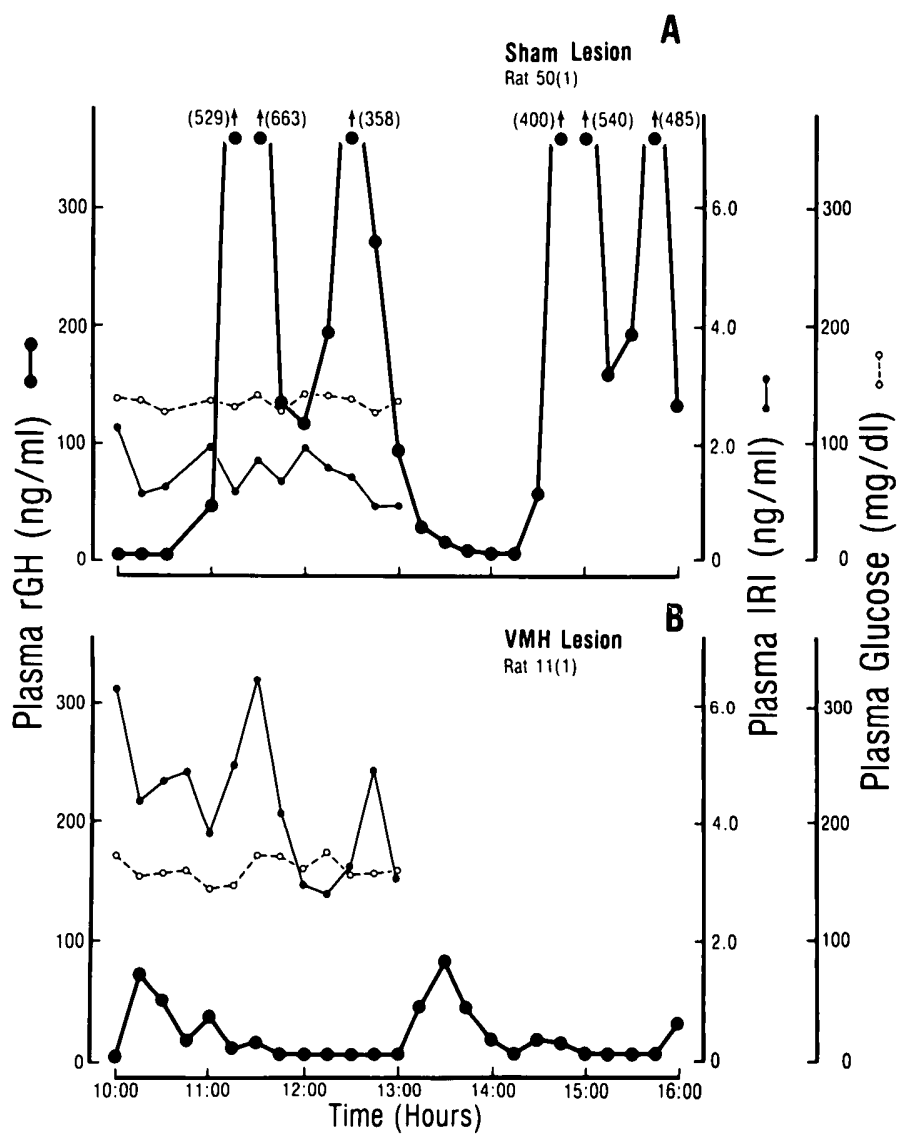

FIG. 2. Individual representative 6 -h plasma GH and 3-h plasma IRI and glucose secretory profiles in a sham-operated rat (A) in comparison to those in an obese VMH-lesioned rat (B). Arrows indicate plasma $\mathrm{GH}$ values (>) $350 \mathrm{ng} / \mathrm{ml}$.

TABLE 1. Mean plasma GH, IRI, and glucose levels in sham-operated and VMH-lesioned rats

\begin{tabular}{lccc}
\hline Experimental group & $\begin{array}{c}\text { Mean 6-h } \\
\text { plasma GH } \\
\text { level (ng/ml) }\end{array}$ & $\begin{array}{c}\text { Mean 3-h } \\
\text { plasma IRI } \\
\text { level (ng/ } \\
\text { ml) }\end{array}$ & $\begin{array}{c}\text { Mean 3-h } \\
\text { plasma glu- } \\
\text { cose level } \\
\text { (mg/dl) }\end{array}$ \\
\hline Sham lesion (7) & $154.1 \pm 17.8$ & $0.99 \pm 0.18$ & $140.7 \pm 2.4$ \\
VMH lesion (6) & $17.6 \pm 6.0^{a}$ & $3.59 \pm 0.83^{b}$ & $137.5 \pm 5.4$ \\
VMH lesion + NSS (5) & $21.2 \pm 9.6$ & $2.59 \pm 1.17$ & $130.4 \pm 7.6$ \\
VMH lesion + SRIF AS & $23.4 \pm 7.1^{c}$ & $3.86 \pm 1.14$ & $133.9 \pm 6.8$ \\
$\quad$ (4) & & & \\
Sham lesion + SRIF AS & $177.4 \pm 34.8$ & $1.19 \pm 0.36$ & $137.9 \pm 3.8$ \\
$\quad(4)$ & & & \\
\hline
\end{tabular}

Values given are the mean \pm SEM; the number of animals in each group is shown in parentheses.

${ }^{a} P<0.001$ vs. sham lesion.

${ }^{b} P<0.05$ vs. sham lesion.

${ }^{c} P<0.005$ vs. sham lesion + SRIF AS.

contrast, the 6-h GH profile of obese-VMH rats showed a marked suppression in amplitude and duration of $\mathrm{GH}$ secretory episodes. In these rats, peak GH levels rarely exceeded $90 \mathrm{ng} / \mathrm{ml}$, and a large proportion of plasma $\mathrm{GH}$ values were undetectable (Fig. $2 \mathrm{~B}$ ). When distinct epi- 
sodes were discernible (four of six rats), the characteristic ultradian rhythm of GH secretion was evident. The mean period of the GH rhythm in VMH-lesioned rats (3.06 \pm $0.28 \mathrm{~h}$ ) was similar to that observed in sham-operated controls ( $3.32 \pm 0.22 \mathrm{~h}$ ). However, there was no evidence of entrainment of the GH pulses to the light-dark (L-D) cycle in VMH-lesioned rats; GH secretory bursts occurred randomly throughout the 6 -h sampling period. Figure 3 illustrates the mean 6 -h plasma GH levels of the two groups of rats. It is evident that mean plasma GH levels were severely suppressed in VMH-lesioned animals (17.6 \pm 6.0 vs. $154.1 \pm 17.8 \mathrm{ng} / \mathrm{ml} ; P<0.001$; Table 1). Furthermore, distinct peaks and troughs were not observed in the mean 6 -h GH profile of these rats (Fig. 3B). This is in contrast to the entrained pattern of GH secretion observed in sham-operated control rats (Fig. 3A).

\section{Effects of SRIF AS on GH, IRI, and glucose secretory profiles in obese-VMH rats}

Individual GH, IRI, and glucose secretory profiles in a VMH-lesioned rat administered NSS were compared to those of the same rat administered SRIF AS 5 days later

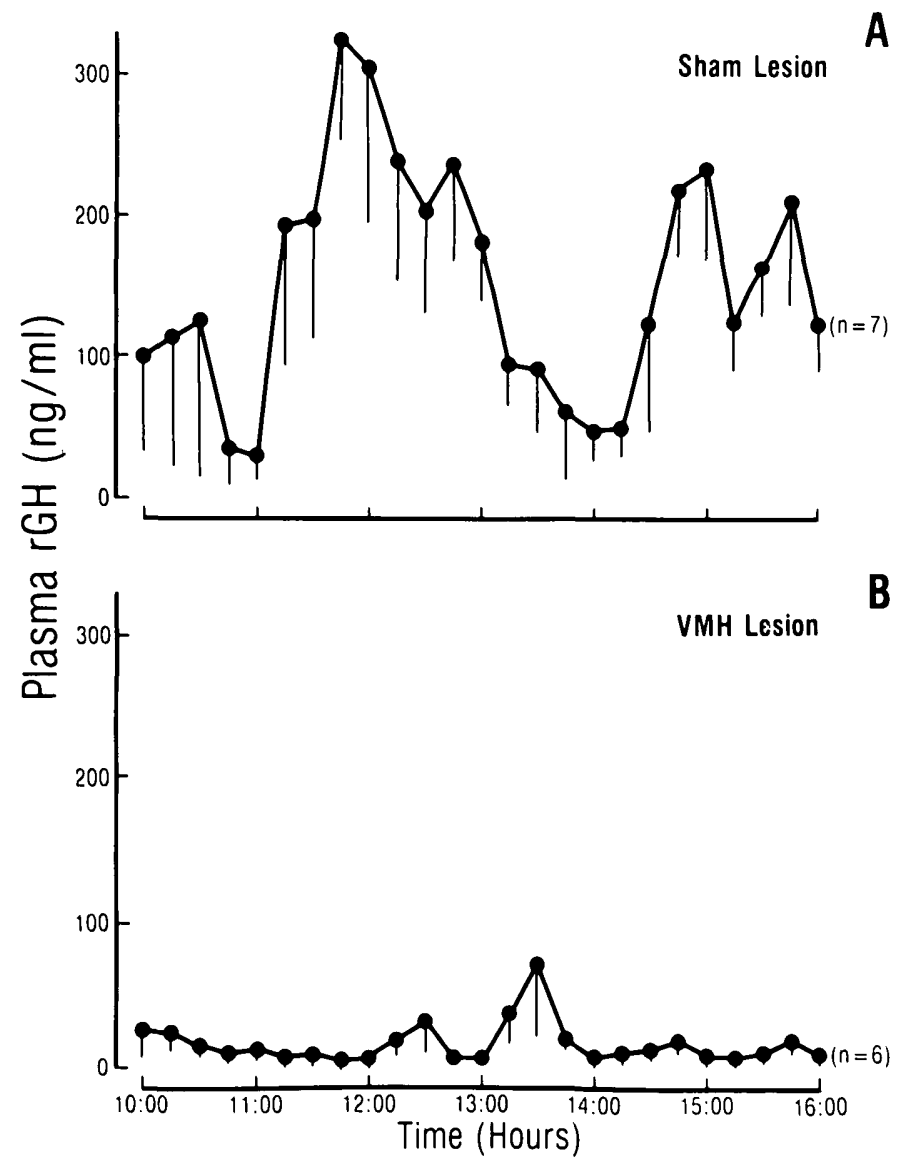

FIG. 3. Effects of VMH lesions on mean 6-h plasma GH levels. Vertical lines represent the SEM. The number of animals in each group is shown in parentheses.
(Fig. 4). In both cases, plasma IRI levels continued to be elevated and fluctuated markedly. The administration of SRIF AS had no significant effect on either plasma IRI or glucose levels (Table 1).

The GH profiles of VMH-lesioned rats receiving NSS still showed the marked suppression in GH pulse amplitude (Figs. 4A and 5), similar to that described above. Administration of SRIF AS to these rats failed to restore the amplitude of the GH pulses or significantly alter the GH secretory profile (Figs. 4B and 5). While plasma GH levels were slightly elevated $15 \mathrm{~min}$ post-SRIF AS administration, this effect was not significant. In addition, GH trough values were only minimally elevated compared to those of NSS controls (Fig. 5). There was no significant difference in mean peak, trough, or 6-h plasma GH level in VMH-lesioned rats administered SRIF AS compared to those given NSS (Fig. 5 and Table 1).

Figure 6 illustrates the plasma GH, IRI, and glucose responses to SRIF AS in a sham-operated control rat whose normal profile is shown in Fig. 2A. In contrast to what was observed in VMH-lesioned rats, the administration of SRIF AS caused a brief surge of GH secretion within 15-45 min after injection and significant elevation of subsequent GH trough levels. Plasma GH trough values in these animals never fell below $30 \mathrm{ng} / \mathrm{ml}$ during the first $3 \mathrm{~h}$ after SRIF AS injection and did not reach

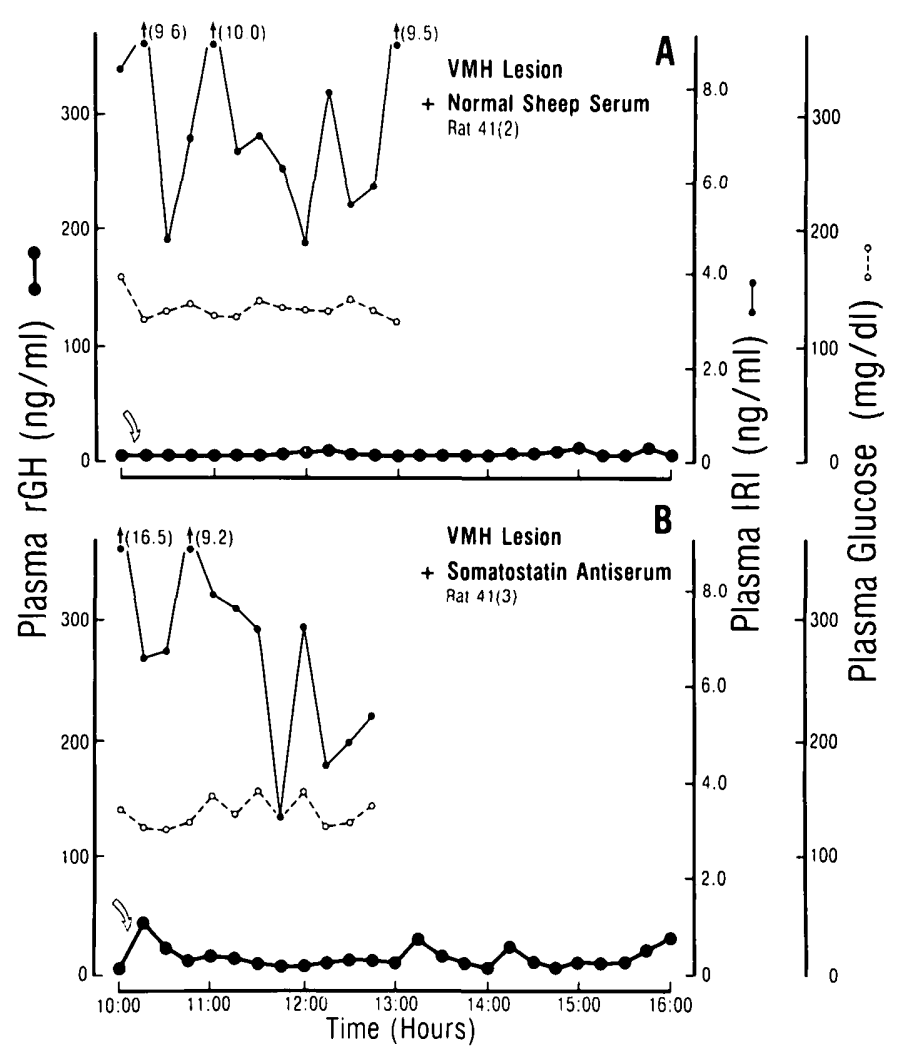

FIG. 4. Individual representative 6 - $\mathrm{h}$ plasma $\mathrm{GH}$ and 3 -h plasma IRI and glucose secretory patterns in the same VMH-lesioned rat administered NSS (A) or SRIF AS 5 days later (B). Curved arrows indicate the time of iv injection. 

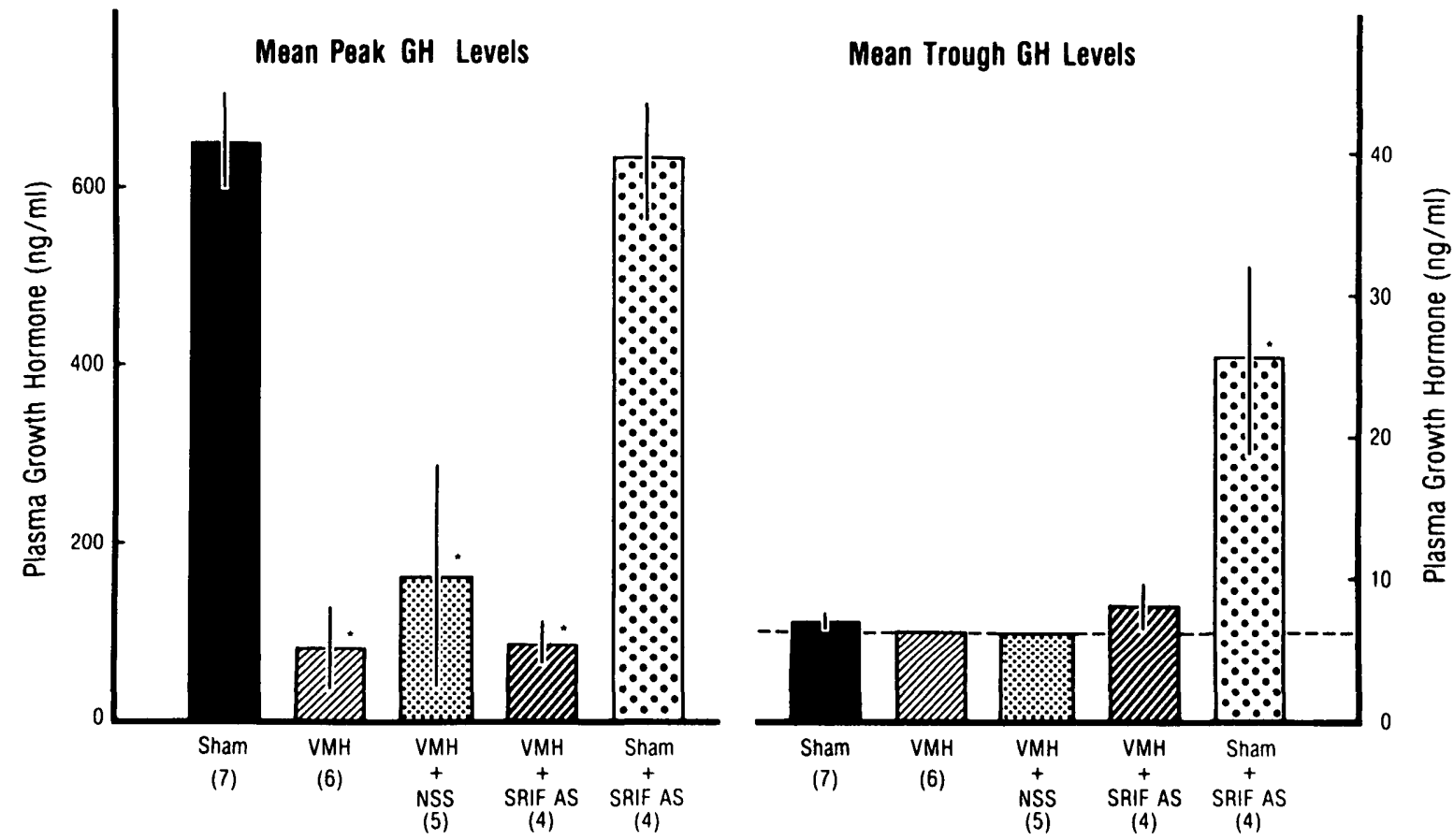

FIG. 5. Mean peak GH levels (highest plasma GH value over the 6-h sampling period) and mean trough GH levels (lowest plasma GH value over the 6-h sampling period) in the five groups of rats. Each bar represents the mean \pm SEM, and the number of animals in each group is shown in parentheses. - - , Least detectable concentration in the rat GH $(\mathrm{rGH})$ RIA. ${ }^{*}, P<0.01$ vs. all other groups without asterisks.

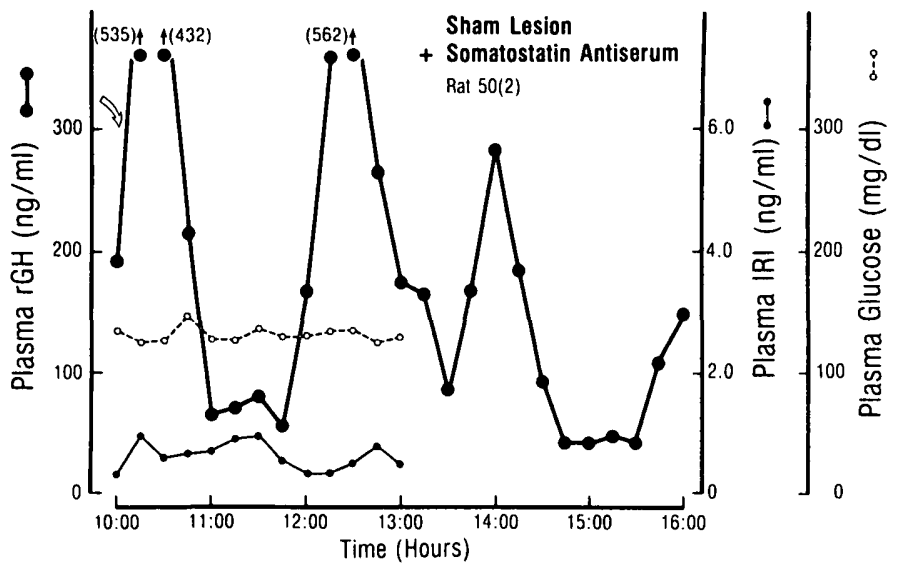

FIG. 6. Effects of SRIF AS on plasma profiles of GH, IRI, and glucose in a sham-operated rat whose normal profile is shown in Fig. 2A. The curved arrow indicates the time of iv injection.

undetectable levels throughout the 6-h sampling period. The mean GH trough level of sham-operated, SRIF AStreated rats was significantly $(P<0.01)$ higher than that of all other groups (Fig. 5). However there was no significant effect of SRIF AS on either mean amplitude of GH peaks (Fig. 5) or mean 6-h plasma GH level (Table 1). There was also no significant effect of SRIF AS on either plasma IRI or glucose levels in sham-operated, SRIF AS-treated rats (Table 1).

\section{SRIF binding of rat plasma after SRIF AS administra-} tion

The mean binding of a 1:100 dilution of plasma $1 \mathrm{~min}$ before and $15 \mathrm{~min}, 3 \mathrm{~h}$, and $6 \mathrm{~h}$ after SRIF AS treatment was found to be $1.4 \pm .3 \%, 42.2 \pm 1.4 \%, 39.8 \pm 0.7 \%$, and $36.1 \pm 1.0 \%$, respectively. Although the binding at 1600 $\mathrm{h}$ was significantly less than that at $1015 \mathrm{~h}(P<0.05)$, it was still substantial.

\section{Effect of VMH lesions on pituitary GH concentration}

Table 2 documents that the obese-VMH rats in the second experiment exhibited hyperinsulinemia and normoglycemia similar to those observed in Exp 1. Furthermore, not unexpectedly, the VMH-lesioned rats were also hyperphagic (mean daily food intake, $52.6 \pm 5.0 \mathrm{vs}$. 33.3 $\pm 1.5 \mathrm{~g}$ in sham-operated controls). Sixteen days after surgery, lesioned rats showed a significant reduction in pituitary wet weight and in pituitary GH content and concentration compared to values in sham-operated controls (Table 2).

\section{Discussion}

The finding that obese-VMH rats exhibit hyperinsulinemia in the presence of normoglycemia confirms similar observations in previous studies $(1,2)$. Of interest in the present study is the pulsatile nature of IRI secretion observed in VMH-lesioned animals. Basal plasma IRI levels showed wide oscillations over the 3 -h sampling period (while plasma glucose levels remained stable), a finding that was probably missed in earlier studies in which only single blood samples were obtained. The mechanism mediating the stimulation of IRI secretion 
TABLE 2. Effect of VMH lesions on the pituitary GH concentration

\begin{tabular}{|c|c|c|c|c|c|c|c|}
\hline \multirow[b]{2}{*}{ Group } & \multirow[b]{2}{*}{$\begin{array}{c}\text { Daily wt gain } \\
\text { (g) }\end{array}$} & \multirow[b]{2}{*}{$\begin{array}{l}\text { Daily food con- } \\
\text { sumption } \\
\text { (g) }{ }^{a}\end{array}$} & \multirow[b]{2}{*}{$\begin{array}{c}\text { Plasma IRI } \\
(\mathrm{ng} / \mathrm{ml})\end{array}$} & \multirow[b]{2}{*}{$\begin{array}{l}\text { Plasma glucose } \\
\text { (mg/dl) }\end{array}$} & \multicolumn{3}{|c|}{ Pituitary } \\
\hline & & & & & $\begin{array}{c}\text { Wet wt } \\
\text { (mg) }\end{array}$ & $\begin{array}{l}\text { GH content } \\
(\mu \mathrm{g} / \text { gland })\end{array}$ & $\begin{array}{l}\text { GH conc. } \\
(\mu \mathrm{g} / \mathrm{mg} \text { wet } \\
\text { wt })\end{array}$ \\
\hline Sham lesion (9) & $4.7 \pm 0.2$ & $33.3 \pm 1.5$ & $1.31 \pm 0.25$ & $131.3 \pm 4.1$ & $12.01 \pm 0.46$ & $1731.0 \pm 127.9$ & $144.2 \pm 8.2$ \\
\hline VMH lesion (8) & $8.7 \pm 0.7$ & $52.6 \pm 5.0^{b}$ & $8.76 \pm 1.52^{c}$ & $135.3 \pm 5.7$ & $8.95 \pm 0.50^{c}$ & $790.0 \pm 108.4^{c}$ & $87.2 \pm 8.0^{\circ}$ \\
\hline
\end{tabular}

has been variously attributed to either direct disruption of neural connections between the hypothalamus and pancreas (e.g. vagus nerve) (24) or indirectly to a humoral factor(s) released after hypothalamic injury $(25,26)$. It is possible that the oscillations in plasma IRI are the result of disinhibition of a recently described intrinsic pancreatic IRI rhythm (27). Further work is necessary to clarify the mechanism responsible for these IRI fluctuations and to determine whether the other pancreatic hormones show similar oscillations as a result of VMH damage.

The ultradian GH rhythm was dramatically altered in obese-VMH rats. Their plasma GH profiles revealed a marked reduction in both amplitude and duration of GH secretory episodes compared to those in sham-operated control animals. These results indicate that GH secretion is severely impaired in obese as well as nonobese VMHlesioned rats and provide further support for the hypothesis that the $\mathrm{VMH}$ region of the brainicontains the neural substrates governing pulsatile GH secretion $(10,12,28)$. The minimal episodic GH release observed in the present study may reflect residual functioning of this system. The finding that the periodicity of the GH rhythm was maintained while L-D entrainment of the GH pulses was lost suggests that different neural circuits subserve these two parameters of the GH rhythm. The L-D entrainment of the GH rhythm has been shown to be disturbed by suprachiasmatic lesions (29) as well as by knife cuts anterior to the VMH (30), a pathway that was probably disrupted by the present VMH lesions.

The findings on $\mathrm{GH}$ in the present study are very similar to those recently reported in rats neonatally administered monosodium glutamate, an agent which selectively destroys neuronal perikarya in the ARC nucleus of the hypothalamus but spares the VMH (31-33). This raises a question as to the involvement of the $\mathrm{VMH}$, per se, in GH regulation. Since the present lesions infringed on the ARC nuclei, it is possible that the observed aberrations of the GH rhythm are due solely to the ARC damage. On the other hand, evidence implicating the $\mathrm{VMH}$ as an important neural locus harboring the puta- tive GRF neurons is impressive in that electrical stimulation of the VMH nuclei produced consistent rises in plasma GH (34-36), although current spread to the ARC cannot be ruled out in these studies. Furthermore, Bernardis and Frohman (9) demonstrated significant decreases in basal plasma GH levels in weanling rats as a result of small lesions limited to the $\mathrm{VMH}$, and reported progressive decreases as lesion size increased, with consequent infringement on the ARC nuclei. Taken together, these findings suggest that both the VMH and ARC regions of the central nervous system are stimulatory to GH secretion.

One potential explanation for the observed changes in plasma GH levels may be related to direct pituitary dysfunction. In the present study, both pituitary wet weight and pituitary GH concentration were significantly reduced 16 days after the lesion. These results are in agreement with the majority of previous reports $(6,8,9$, 19). Only those studies in which the pituitary GH concentration was measured within $48 \mathrm{~h}$ after surgery (1.7, 18) report no effect of the lesion, suggesting that the pituitary GH depletion is gradual. A similar reduction of the pituitary GH concentration has been reported in most studies of monosodium glutamate-treated rats (31, 37), but not all (33). It is unlikely, however, that the plasma GH suppression was due solely to pituitary insufficiency for the following reasons. First, the plasma GH suppression should then parallel the pituitary disturbance; thus, the effect should be minimal early after the lesion and then gradually increase, but no such time course was observed in the present study. Second, the pituitary gland is considered to maintain its function in VMH-lesioned animals, since TRH has been shown to cause $\mathrm{GH}$ release $(19,38)$ despite a reduction in pituitary wet weight and GH content (19). Finally, in another model of hypothalamic injury (periventricular lesions), basal plasma GH levels have been shown to be elevated or at least normal in the face of significant reductions in the pituitary GH concentration (39). Thus, it seems reasonable to conclude that the suppression of $\mathrm{GH}$ pulse amplitude observed in VMH-lesioned animals is a direct 
result of central nervous system intervention.

A second possible explanation may be related to disruption of the somatostatinergic neuronal system involved in $\mathrm{GH}$ regulation. That is, the $\mathrm{GH}$ suppression could be due to increased release of SRIF into the hypophyseal portal circulation. The finding that passive immunization with a specific antiserum to SRIF failed to restore the amplitude of $\mathrm{GH}$ pulses or to alter significantly the GH secretory profile of VMH-lesioned rats argues against this possibility. These findings differ from our previous passive immunization studies in which the same SRIF AS resulted in both a restoration of high amplitude GH pulses and an increase in mean plasma GH levels in starved (15) and diabetic (16) rats exhibiting suppressed plasma GH levels. It is unlikely that inadequate passive immunization can account for the lack of effect, since significant SRIF antibody titers were present throughout the sampling period. The results indicate that increased SRIF release is not the mechanism whereby VMH lesions cause suppression of GH secretion. These data provide good evidence that the suppression of $\mathrm{GH}$ pulses observed in response to $\mathrm{VMH}$ lesions is due to interruption of stimulatory pathways involved in $\mathrm{GH}$ regulation, e.g. putative GRF neurons. The findings suggest that the ultradian surges of $\mathrm{GH}$ release in the rat are dependent on the release of GRF from the VMH$\mathrm{ARC}$ region of the brain.

In addition, VMH-lesioned rats did not exhibit the typical elevation of GH trough levels after SRIF AS administration, a response that was evident in sham rats of the present study and has previously been well documented to be the major effect of SRIF AS in normal rats in both this $(40,41)$ and other laboratories (42). It has been reported that lesions of the VMH result in an approximately $50 \%$ decrease in median eminence SRIF (43). Thus, in addition to disruption of the GRF system, SRIF release into the hypophyseal portal circulation may also be impaired in VMH-lesioned animals. A similar lack of response to SRIF AS administration has been documented in anesthetized rats exposed to ablation of the medial basal hypothalamus ( $\mathrm{MBH})$, indicating that an intact $\mathrm{MBH}$ may be necessary to elicit the $\mathrm{GH}$ response to SRIF AS (44). It is highly unlikely that the $\mathrm{GH}$ suppression in VMH-lesioned rats is due to disruption of SRIF release, since the results of several previous studies indicate that selective lesions of the primary somatostatinergic neuronal system, including the anterior hypothalamic-preoptic area $(45,46)$ or separation of this area from the $\mathrm{MBH}(30,47)$, markedly augment plasma $\mathrm{GH}$ levels.

The joint occurrence of VMH lesion-induced obesity and $\mathrm{GH}$ suppression raises the possibility that they may be causally related. It is known that in man, obesity results in impaired GH release, which is restored when the obesity is corrected (48). However, it is unlikely that the GH suppression observed in the present study is secondary to the obesity, since similar suppression has been reported in nonobese, VMH-lesioned animals (10). The possibility that the GH suppression plays a role in producing the obesity must be considered. GH is known to influence the intermediary metabolism of lipids; it induces mobilization of fat from adipose tissue, and impaired GH secretion could result in a greater accumulation of fat (49). Furthermore, it has been reported that GH administration to hypophysectomized, VMH-lesioned rats prevents the lesion-induced obesity (50). However, marked obesity has also been observed in the presence of elevated plasma GH levels in animals with surgical isolation of the $\mathrm{MBH}(30,47,51)$. Thus, it is possible to observe hypothalamic obesity in rats exhibiting both suppression and hypersecretion of GH. These findings tend to confirm an earlier suggestion (9) that in the VMH-lesioned rat, the resulting obesity and $\mathrm{GH}$ disturbance reflect the disruption of two different neuronal systems.

\section{Acknowledgments}

A special note of thanks to Miss Laura Wanamaker for performing the RIAs and drawing the figures and to Mrs. Wendy Gurd for surgical assistance. We thank the NIAMDD for the generous supplies of rat GH RIA materials, Dr. R. Chance, Eli Lilly Co., for the gift of rat insulin, and Mrs. Mary Youakim for her expert secretarial assistance.

\section{References}

1. Powley T 1977 The ventromedial hypothalamic syndrome, satiety and a cephalic phase hypothesis. Psychol Rev 84:89

2. Bray GA, York DA 1979 Hypothalamic and genetic obesity in experimental animals: an autonomic and endocrine hypothesis. Physiol Rev 59:719

3. Hetherington AW, Ranson SW 1940 Hypothalamic lesions and adiposity.in the rat. Anat Rec 78:149

4. Bogdanove EM, Lipner HJ 1952 Intestinal absorption of glucose in hypothalamic obesity. Proc Soc Exp Biol Med 81:410

5. Reichlin S 1960 Growth and the hypothalamus. Endocrinology $67: 760$

6. Reichlin S 1961 Growth hormone content of pituitaries from rats with hypothalamic lesions. Endocrinology 69:225

7. Bernardis LL, Skelton FR 1966 Growth and obesity following ventromedial hypothalamic lesions placed in female rats at four different ages. Neuroendocrinology 1:265

8. Frohman LA, Bernardis LL 1968 Growth hormone and insulin levels in weanling rats with ventromedial hypothalamic lesions. Endocrinology 82:1125

9. Bernardis LL, Frohman LA 1970 Effect of lesion size in the ventromedial hypothalamus on growth hormone and insulin levels in weanling rats. Neuroendocrinology 6:319

10. Martin JB, Renaud LP, Brazeau P 1974 Pulsatile growth hormone secretion: suppression by hypothalamic ventromedial lesions and by long-acting somatostatin. Science 186:538

11. Tannenbaum GS, Martin JB 1976 Evidence for an endogenous ultradian rhythm governing growth hormone secretion in the rat. Endocrinology 98:562

12. Martin JB, Brazeau P, Tannenbaum GS, Willoughby JO, Epelbaum J, Terry LC, Durand D 1978 Neuroendocrine organization of growth hormone regulation. In: Reichlin S, Baldessarini R, Martin JB (eds) 
The Hypothalamus. Raven Press, New York, p 329

13. Terry LC, Willoughby JO, Brazeau P, Martin JB, Patel Y 1976 Antiserum to somatostatin prevents stress-induced inhibition of growth hormone in the rat. Science 192:565

14. Arimura A, Smith WD, Schally AV 1976 Blockade of the stressinduced decrease in blood GH by antisomatostatin serum in rats. Endocrinology 98:540

15. Tannenbaum GS, Epelbaum J, Colle E, Brazeau P, Martin JB 1978 Antiserum to somatostatin reverses starvation-induced inhibition of growth hormone but not insulin secretion. Endocrinology 102:1909

16. Tannenbaum GS 1981 Growth hormone secretory dynamics in streptozotocin diabetes: evidence of a role for endogenous circulating somatostatin. Endocrinology 108:76

17. Martin JM, Konijnendijk W, Bouman PR 1974 Insulin and growth hormone secretion in rats with ventromedial hypothalamic lesions maintained on restricted food intake. Diabetes 23:203

18. Martin JB, Audet J, Saunders A 1975 Effects of somatostatin and hypothalamic ventromedial lesions on $\mathrm{GH}$ release induced by morphine. Endocrinology 96:839

19. Muller EE, Panerai AE, Cocchi D, Gil-ad I, Rossi GL, Olgiati VR 1977 Growth hormone releasing activity of thyrotropin-releasing hormone in rats with hypothalamic lesions. Endocrinology 100:1663

20. Pellegrino LJ, Cushman AJ 1967 A Stereotaxic Atlas of the Rat Brain. Appleton-Century-Crofts, New York

21. Herbert V, Lau KS, Gottlieb CW, Bleicher SJ 1965 Coated charcoal immunoassay of insulin. J Clin Endocrinol Metab 25:1375

22. Tannenbaum GS, Rorstad O, Brazeau P 1979 Effects of prolonged food deprivation on the ultradian growth hormone rhythm and immunoreactive somatostatin tissue levels in the rat. Endocrinology 104:1733

23. Winer BJ 1971 Statistical Principles in Experimental Design, ed 2. McGraw-Hill, New York

24. Berthoud HR, Jeanrenaud B 1979 Acute hyperinsulinemia and its reversal by vagotomy after lesions of the ventromedial hypothalamus in anesthetized rats. Endocrinology 105:146

25. Idahl LA, Martin JM 1971 Stimulation of insulin release by a ventrolateral hypothalamic factor. J Endocrinol 51:601

26. Moltz JH, Fawcett CP, McCann SM, Dobbs RE, Unger RH 1975 The hypothalamo-pancreatic axis: evidence for a neurohormonal pathway in the control of the release of insulin and glucagon. Endocr Res Commun 2:537

27. Stagner JI, Samols E, Weir GC 1980 Sustained oscillations of insulin, glucagon, and somatostatin from the isolated canine pancreas during exposure to a constant glucose concentration. J Clin Invest 65:939

28. Krulich L, Illner P, Fawcett CP, Quijada M, McCann SM 1972 Dual hypothalamic regulation of growth hormone secretion. In: Pecile A, Müller EE (eds) Growth and Growth Hormone. Excerpta Medica, Amsterdam, p 306

29. Willoughby JO, Martin JB 1978 The suprachiasmatic nucleus synchronizes growth hormone secretory rhythms with the light-dark cycle. Brain Res 151:413

30. Willoughby JO, Terry LC, Brazeau P, Martin JB 1977 Pulsatile growth hormone, prolactin, and thyrotropin secretion in rats with hypothalamic deafferentation. Brain Res 127:137

31. Terry LC, Epelbaum J, Martin JB 1981 Monosodium glutamate: acute and chronic effects on rhythmic growth hormone and prolactin secretion, and somatostatin in the undisturbed male rat. Brain Res 217:129

32. Millard WJ, Reppert SM, Sagar SM, Martin JB 1981 Light-dark entrainment of the growth hormone ultradian rhythm in the rat is mediated by the arcuate nucleus. Endocrinology 108:2394

33. Millard WJ, Martin Jr JB, Audet J, Sagar SM, Martin JB 1982 Evidence that reduced growth hormone secretion observed in monosodium glutamate-treated rats is the result of a deficiency in growth hormone releasing factor. Endocrinology 110:540

34. Frohman LA, Bernardis LL, Kant KJ 1968 Hypothalamic stimulation of growth hormone secretion. Science 162:580

35. Bernardis LL, Frohman LA 1971 Plasma growth hormone responses to electrical stimulation of the hypothalamus in the rat. Neuroendocrinology 7:193

36. Martin JB 1972 Plasma growth hormone (GH) response to hypothalamic or extrahypothalamic electrical stimulation. Endocrinology 91:107

37. Redding TW, Schally AV, Arimura A, Wakabayashi I 1971 Effect of monosodium glutamate on some endocrine function. Neuroendocrinology 8:245

38. Chihara K, Kato Y, Ohgo S, Iwasaki Y, Abe H, Maeda K, Imura H 1976 Stimulating and inhibiting effects of thyrotropin-releasing hormone on growth hormone release in rats. Endocrinology 98:1047

39. Critchlow V, Abe K, Urman S, Vale W 1981 Effects of lesions in the periventricular nucleus of the preoptic-anterior hypothalamus on growth hormone and thyrotropin secretion and brain somatostatin. Brain Res 222:267

40. Tannenbaum GS, Gurd W, Wanamaker L, Fong J 1980 Effects of systemic and central administration of somatostatin antiserum on pituitary and pancreatic hormone secretion. Clin Res 28:704A (Abstract)

41. Tannenbaum GS, Studies on the mechanism for "short-loop" feedback control of growth hormone secretion. In: Raptis S, Gerich JE (eds) Proceedings of the Second International Symposium on Somatostatin. Academic Press, London, in press

42. Terry LC, Martin JB 1981 The effects of lateral hypothalamicmedial forebrain stimulation and somatostatin antiserum on pulsatile growth hormone secretion in freely behaving rats: evidence for a dual regulatory mechanism. Endocrinology 109:622

43. Epelbaum J, Willoughby JO, Brazeau P, Martin JB 1977 Effects of brain lesions and hypothalamic deafferentation on somatostatin distribution in the rat brain. Endocrinology 101:1495

44. Chihara K, Arimura A, Chihara M, Schally AV 1978 Studies on the mechanism of growth hormone and thyrotropin response to somatostatin antiserum in anesthetized rats. Endocrinology 103:1916

45. Rice RW, Critchlow V 1976 Extrahypothalamic control of stressinduced inhibition of growth hormone secretion in the rat. Endocrinology 99:970

46. Willoughby JO, Martin JB 1978 Pulsatile growth hormone secretion: inhibitory role of medial preoptic area. Brain Res 148:240

47. Mitchell JA, Hutchins M, Schindler WJ, Critchlow V 1973 Increases in plasma growth hormone concentration and naso-anal length in rats following isolation of the medial basal hypothalamus. Neuroendocrinology 12:161

48. Glass AR, Burman KD, Dahms WT, Boehm TM 1981 Endocrine function in human obesity. Metabolism 30:89

49. Goodman HM, Schwartz J 1974 Growth hormone and lipid metabolism. In: Knobil E, Sawyer WH (eds) Handbook of Physiology, sect 7, vol 4, part 2. American Physiological Society, Washington DC, $\mathrm{p} 211$

50. York DA, Bray GA 1972 Dependence of hypothalamic obesity on insulin, the pituitary and the adrenal gland. Endocrinology 90:885

51. Rice RW, Kroning J, Critchlow V 1976 Sex differences in the effects of surgical isolation of the medial basal hypothalamus on linear growth and plasma growth hormone levels in the rat. Endocrinology 98:982 